\title{
Idazoxan and 8-OH-DPAT Modify the Behavioral Effects Induced by Either NA, or 5-HT, or Dual NA/5-HT Reuptake Inhibition in the Rat Forced Swimming Test
}

Jean-Philippe Rénéric, M.D., Ph.D., Manuel Bouvard, M.D., Ph.D., and Luis Stinus, Ph.D.

The rat forced swimming test (FST) predicts the efficacy of antidepressants, which decrease immobility duration in the test, and can distinguish selective serotonin (5-HT) and noradrenaline (NA) reuptake inhibitors, which, respectively, increase swimming and climbing behaviors. However, dual 5-HT and NA reuptake-inhibition produces climbing behavior solely, thereby suggesting with other data that the NA-system mediates inhibiting interactions on 5-HT-induced swimming in the FST. Since $\alpha_{2}$ -

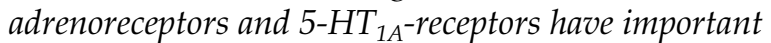
regulatory functions and are involved in 5-HT/NA interactions, we examined whether the $\alpha_{2}$-receptor-

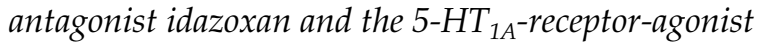
8-hydroxy-2-(di-n-propylamino)-tetralin (8-OH-DPAT) would modify the behavioral pattern induced in the FST by either selective or non-selective antidepressant treatments. The rats were treated subacutely ( 3 injections IP over 48 h) with: (a) idazoxan $(0.5-10 \mathrm{mg} / \mathrm{kg}$ ) alone, and in combination with desipramine $(10 \mathrm{mg} / \mathrm{kg})$, or desipramine + fluoxetine $(10 / 10 \mathrm{mg} / \mathrm{kg})$, or the dual serotonin/ noradrenaline reuptake-inhibitor milnacipran $(20 \mathrm{mg} / \mathrm{kg})$. (b) 8-OH-DPAT (0.25-1 mg/kg) alone, and in combination with either desipramine $(10 \mathrm{mg} / \mathrm{kg})$ or fluoxetine $(10 \mathrm{mg} /$ $\mathrm{kg})$. The results indicated: (a) Idazoxan $(0.5,5,10 \mathrm{mg} / \mathrm{kg}$ ) produced no anti-immobility effects per se in the FST, antagonized the effects of the NA-reuptake-inhibitor desipramine, and allowed desipramine + fluoxetine, as well as milnacipran, to increase swimming behavior. (b) 8-OH-DPAT produced non-significant effects per se, potentiated desipramine-induced antidepressant-like effects on immobility and climbing, and both antagonized swimming and produced climbing behavior in combination with fluoxetine. Our data support clinical trials suggesting

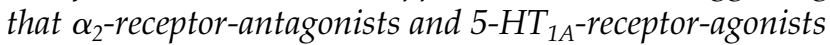
may be of interest in augmentation strategies for antidepressant treatments. The scoring of active behaviors in the FST appears to be an interesting tool for studying 5-HT/NA interactions induced by antidepressants, as well as for the testing of augmentation strategies.

[Neuropsychopharmacology 24:379-390, 2001] (C) 2001 American College of Neuropsychopharmacology. Published by Elsevier Science Inc.
From the Laboratoire de Neuropsychobiologie des Désadaptations, CNRS-UMR 5541, Université Bordeaux2, Bordeaux, [DNY] France (J-PR, LS); and the Service Universitaire de Psychiatrie de l'Enfant et de l'Adolescent, Université de Bordeaux2, Bordeaux, France (J-PR, MB).

Address correspondence to: Dr. Jean-Philippe Rénéric, Departement Universitaire de Psychiatrie de l'Enfant et de l'Adolescent, C.H.S Ch. Perrens, 121 rue de la Bechade, 33076 Bordeaux Cedex, France. Tel.: (33) 5575715 48; Fax: (33) 5569002 78; E-mail: JeanPhilippe.Reneric@labopsy.u-bordeaux2.fr

Received October 12, 1999; revised August 16, 2000; accepted September 14, 2000.
KEY WORDS: Antidepressants; Forced swimming; Serotonin; Noradrenaline; Interactions; Desipramine; Fluoxetine; Milnacipran; Idazoxan; 8-OH-DPAT

The forced swimming test (FST) is a quick and reliable behavioral test in rodents (Porsolt et al. 1977, 1978, 1979), which detects all the major classes of antidepressant treatments (Borsini and Meli 1988), such as tricyclic antidepressants (TCAs), monoamine oxidase inhibitors 
(MAOIs), atypical antidepressants, and electroconvulsive shock. The FST is also used to investigate the mechanisms of action of antidepressant drugs (Borsini 1995) or the functional interactions that occur when antidepressants are administered (Redrobe and Bourin 1999; Rénéric and Lucki 1998). The rat FST consists of placing the animal in a jar filled with water for a pre-test on day 1 , and for a five-minute test session 24 hours later, with the drugs being administered sub-acutely ( 3 injections) between the two sessions. The animal first attempts to escape and then progressively adopts an immobile posture, making only small movements to keep its head above water. Effective antidepressant treatments decrease the duration of immobility in the test session (Porsolt et al. 1978). Other methods of scoring the FST take into account swimming and climbing, two main active behaviors occurring in the test, which contribute to the antidepressant-like decrease in immobility-duration (Detke et al. 1995b). This procedure showed that noradrenaline (NA)-reuptake inhibitors (NRIs) and selective serotonin (5-hydroxytryptamine/ 5-HT)-reuptake inhibitors (SSRIs) increased selectively and respectively climbing and swimming behavior (Detke et al. 1995b). This technique can thus distinguish components to the behavioral response to antidepressants (Lucki 1997), which is in agreement with distinguishable neurochemical and behavioral contributions to the therapeutic effects of antidepressants in humans (Heninger et al. 1996; Katz et al. 1994).

Serotonin and noradrenaline systems are directly involved in the pathogenesis and the recovery from depression (Blier et al. 1990; Caldecott Hazard et al. 1991), and there were clinical suggestions that simultaneous enhancement of neurotransmission in both 5-HT and NA systems could provide increased efficacy and rapidity of antidepressants effects (Nelson et al. 1991; Poirier and Boyer 1999; Seth et al. 1992; Weilburg et al. 1989). In the FST, however, the NRI desipramine dosedependently antagonized the swimming behavior produced by the SSRI fluoxetine (Rénéric and Lucki 1998). Similarly, milnacipran, which is an equipotent serotonin/noradrenaline reuptake inhibitor (SNRI) (Briley et al. 1996; Moret et al. 1985), produced NA-induced like climbing behavior solely, with no concurrent increase in swimming (Rénéric and Lucki 1998). Since any fluoxetine-induced swimming effects depend on the integrity of the 5-HT-system (Page et al. 1999), our data suggested that enhancement of NA-transmission might block fluoxetine-effects by inhibiting 5-HT-release, possibly through the stimulation of $\alpha_{2}$-heteroreceptors on 5-HT-nerve endings (Clement et al. 1992; Mongeau et al. 1993, 1997; Tao and Hjorth 1992).

The present study was designed to provide more information about greater efficacy of antidepressant treatments that interact with multiple neurotransmitter systems. At first, we hypothesized that $\alpha_{2}$-receptor antagonists such as idazoxan (Doxey et al. 1983), would prevent NA-mediated inhibiting interactions on the 5-HT-system in the FST. Idazoxan might thus potentiate the antidepressant-like effects produced by dual 5-HT/NA reuptake-inhibitors, such as milnacipran or a (fluoxetine + desipramine) combination. Secondly, we examined the effects produced in the FST by combinations of 8-hydroxy-2-(di-n-propylamino)-tetralin (8-OH-DPAT) (Middlemiss and Fozard 1983) with either the NRI desipramine or the SSRI fluoxetine. Indeed, $5-\mathrm{HT}_{1 \mathrm{~A}}$ receptor agonists such as $8-\mathrm{OH}-\mathrm{DPAT}$, buspirone and gepirone, produce SSRI-like effects in the FST (Detke et al. 1995a,c ; Kitamura and Nagatani 1996; Lucki et al. 1994). Those antidepressant-like effects were not prevented by a 5-HT-depletion, thereby suggesting that they are mediated through post-synaptic $5-\mathrm{HT}_{1 \mathrm{~A}}$ receptors (Wieland and Lucki 1990). In this study, we hypothesized that combining NRIs with 8-OH-DPAT in the FST would bypass presynaptic 5-HT/NA interactions, and would thereby result in the summation of NA and 5-HT antidepressant-like effects.

\section{MATERIALS AND METHODS}

All procedures employed in the studies were performed in accordance with the Declaration of Helsinki, the Guide and Use of Laboratory Animals as adopted and promulgated by the U.S. National Institute of Health, the European Communities Council Directives (86/609/EEC, 24 November 1986), and the French Directives concerning the Use of Laboratory Animals (Decret 87-848, 19 October 1987).

\section{Animals}

A total of 369 (FST: 320; locomotor activity: 49) male Sprague-Dawley rats (IFFA-CREDO, Lyon, France) weighing 150-175 g at arrival in the laboratory, were used in these experiments. Animals were housed collectively in groups of four in polycarbonate cages. They were maintained on a $12 \mathrm{hr}$ light-dark cycle (lights on 08:00-20:00 hours) in a temperature controlled $\left(22^{\circ} \mathrm{C}\right)$ colony room. Rats were handled for 3-5 days prior to behavioral testing. Food and water were available ad libitum. These conditions were maintained constant throughout the experiments.

\section{Forced Swimming Test}

The overall procedure consisted in placing the rats in individual plexigas cylinders $(46 \mathrm{~cm}$ tall $\times 20 \mathrm{~cm}$ in diameter) that had previously been filled with water (23$25^{\circ} \mathrm{C}$ ) up to $30 \mathrm{~cm}$ from bottom. The water level was deliberately chosen higher than in the procedure described by Porsolt et al. (1978) to prevent the rats, during the swimming sessions, from supporting themselves 
by touching the bottom with their hind limbs or tail. Drug treatments were administered between these two sessions. At the end of both swimming sessions, the rats were removed from the cylinders, dried with towels, placed in cages for 15 min rest and recovery, and then returned to their home cages. Pre-test and test sessions were videotaped from above the cylinders (Panasonic black and white video cameras, Grundig videotape recorder). Test sessions were scored later by a single rater, blind to the treatment condition.

\section{Drug Treatment}

The following drugs were used in this study: desipramine hydrochloride (Sigma, S-125); idazoxan hydrochloride (Sigmae, I-6138); 8 OH-DPAT hydrobromide (RBI, S-002). Milnacipran hydrochloride (Pierre Fabre Medicament, Castres, France) and fluoxetine hydrochloride (Lilly, Saint Cloud, France) were obtained as generous gifts. The animals were randomly assigned to a treatment, that was administered (three injections) $23.5 \mathrm{hr}, 5$ $\mathrm{hr}$, and $1 \mathrm{hr}$ prior to the start of the test. In all cases, drugs were administered intraperitoneally (IP) in a volume equivalent to $2 \mathrm{ml} / \mathrm{kg}$ and were prepared freshly each morning. Doses were calculated as $\mathrm{mg} / \mathrm{kg}$ base, dissolved in isotonic saline solution $(0.9 \% \mathrm{NaCl})$, except fluoxetine, which was solubilized in deionized water. The control rats received isotonic $0.9 \% \mathrm{NaCl}$ solution. Doses for fluoxetine $(10 \mathrm{mg} / \mathrm{kg})$, desipramine $(10 \mathrm{mg} / \mathrm{kg})$, milnacipran $(20 \mathrm{mg} / \mathrm{kg})$, or fluoxetine/desipramine combination $(10 / 10 \mathrm{mg} / \mathrm{kg})$ were chosen as they produced robust effects in the FST in previous studies and under similar experimental conditions (Rénéric and Lucki 1998). In some experiments, the effects of drug combinations were examined. A single solution was then prepared in order to administer the treatment in one single injection.

\section{Behavioral Scoring}

Three behaviors were scored by using a time-sampling technique that has previously been shown to be both valid and reliable for the detection of antidepressant drugs effects (Detke et al. 1995b). During the viewing of the test-session videotape, a single rater, blind to the treatment condition, scores the rat behavior at the end of each 5-seconds period (i.e., 60 times over the $5 \mathrm{~min}$ test-session), as (1) immobility: floating in the water without struggling, and making only those movements necessary to keep the head above the water; (2) swimming: making active swimming motions, more than necessary to merely keep the head above water (i.e., moving around in the cylinder); and (3) climbing: making active movements with forepaws in and out of the water, usually directed against the walls. Scores for each behavior were expressed as total behavioral counts per 5-min session.

\section{Locomotor Activity}

Locomotor activity was measured by placing the rats individually in activity cages $(35 \times 25 \times 25 \mathrm{~cm})$ : the floor was formed of wire mesh and the sidewalls were made of $10 \mathrm{~mm}$ Plexiglas (Imetronic, Pessac, France). In this apparatus, each passage of the rat interrupted the beams of two infrared photoelectric cells ( $14 \mathrm{~cm}$ apart, 3 $\mathrm{cm}$ above the floor) that were connected to a computer. The total number of beam interruptions on both photocells, represented the total locomotor activity of the rat, and was recorded and analysed by using a computer software (Imetronic, Pessac, France). The locomotor activity was measured for $60 \mathrm{~min}$. Each treatment was tested at the dose which produced the greatest behavioral effect in the FST, and the pattern of administration was similar to that used in the FST experiments.

\section{Experimental Groups}

Each animal was assigned randomly to a treatment, and was used for one pre-test/test session only. For some experiments that required a large number of rats, behavioral data required to be pooled from different test-sessions. In this case, there was no statistical differences between the control groups of the sessions from which data were combined.

\section{Statistical Analysis}

For each experiment, a power analysis as well as a Bonferroni correction were conducted. Forced swimming test data were analyzed using a two-way analysis of variance (ANOVA) with two "between factor" (antidepressant treatment and idazoxan for experiments 1, 2B, 3 ; desipramine and fluoxetine for experiment $2 \mathrm{~A}$; antidepressant treatment and 8-OH-DPAT for experiments $4,5)$. Whenever main factors were found, post-hoc analysis was performed. The Newman-keuls'(NK) test was used to compare experimental groups to controls and to the single drug standard. The Kruskal-Wallis nonparametric rank test examined the dose-dependency of the effects of idazoxan and 8-OH-DPAT on antidepressant treatments (with "doses of idazoxan" as the independent variable). Locomotor activity crosses were compared between groups using a one-factor (treatment) ANOVA analysis, followed by Dunnett's test for comparison to the control group.

\section{RESULTS}

\section{Experiment 1}

The behavioral effects produced in the FST by co-administrations of idazoxan (IDAZ) with desipramine (DMI) 


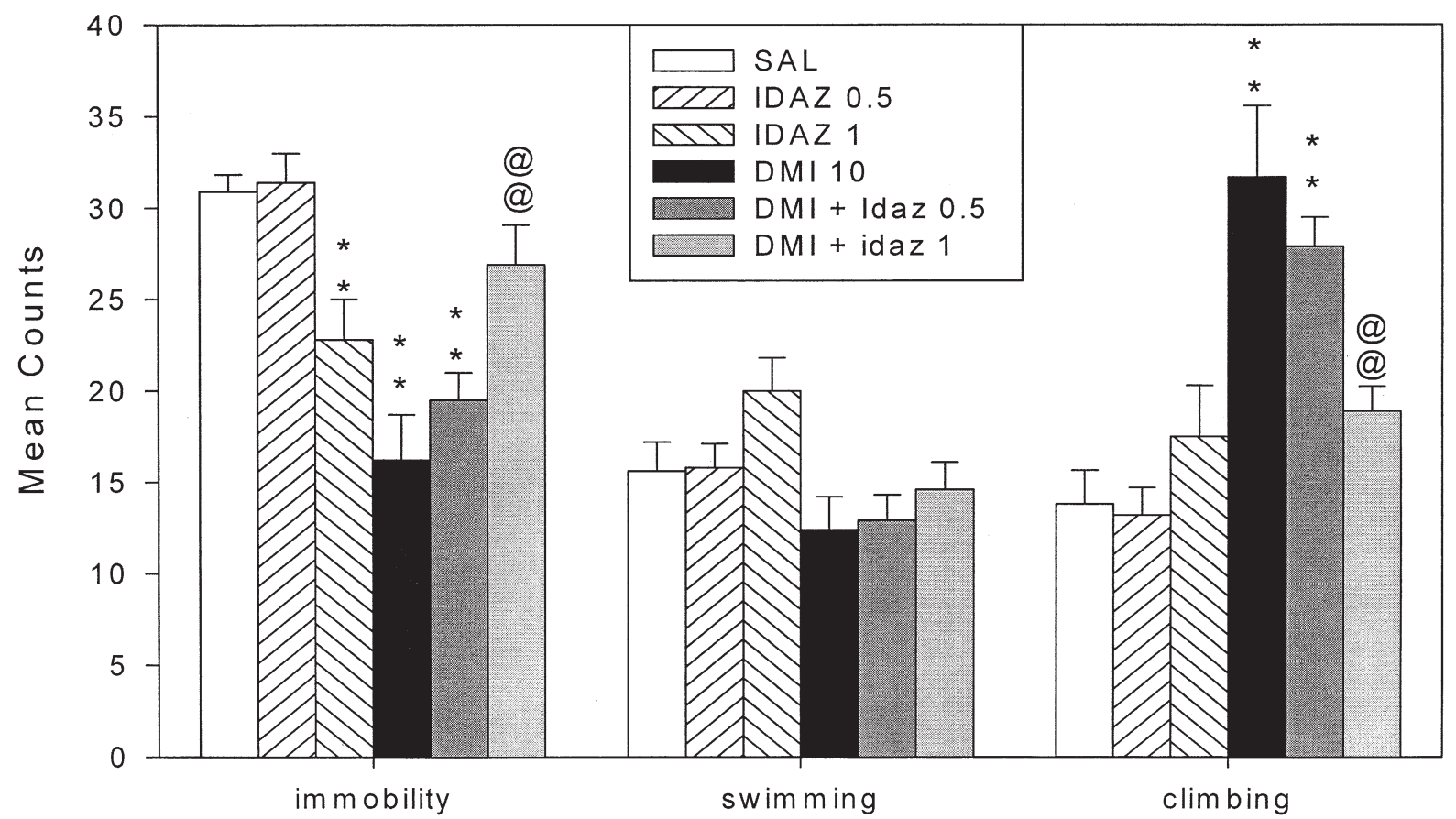

Figure 1. Behavioral effects produced in the FST by co-administrations of idazoxan (IDAZ: 0.5, $1 \mathrm{mg} / \mathrm{kg}$ ) with desipramine (DMI: $10 \mathrm{mg} / \mathrm{kg})(\mathrm{n}=66)$. Values represent mean $( \pm \mathrm{SEM})$ counts of immobility, swimming and climbing behaviors when sampled every $5 \mathrm{~s}$ during the $5 \mathrm{~min}$ test period. Differences in comparison to control group (SAL: $\mathrm{n}=17$ ): ${ }^{* *} p<.01$. Differences in comparison to desipramine group (DMI 10: $\mathrm{n}=10)$ : @ $p<.05$, @@ $<<.01$. [IDAZ 0.5: $\mathrm{n}=11 ;$ IDAZ 1: $\mathrm{n}=8 ;(\mathrm{DMI}+$ Idaz 0.5): $\mathrm{n}=10$; (DMI + Idaz 1): $\mathrm{n}=10]$.

are shown in Figure 1. The DMI-induced decrease in immobility duration $[\mathrm{F}(1,65)=26.45, p<.01]$, was antagonized by IDAZ $[\mathrm{F}(2,60)=15.3, p<.01]$. DMI overall induced changes in swimming $[\mathrm{F}(1,65)=8.52, p<$ $.05]$, but not IDAZ. There was no DMI $\times$ IDAZ interaction for swimming. The DMI-induced increase in climbing $[\mathrm{F}(1,65)=35, p<.01]$ was antagonized by IDAZ $[\mathrm{F}(2,60)=6.6, p<.05]$, in a dose-dependent manner (Kruskal-Wallis, $\mathrm{H}(2)=11, p<.05)$.

\section{Experiment 2A}

The behavioral effects produced in the FST by a fluoxetine (FLU) with desipramine (DMI) combination (DF) are shown in Figure 2A. Immobility: DMI $[\mathrm{F}(1,44)=22, p<$ $.01]$, FLU $[\mathrm{F}(1,44)=12, p<.01]$, and $\mathrm{DF}[\mathrm{F}(1,41)=13.5$, $p<.01$ ] decreased immobility duration (NK: $p<.01$ for each group). Swimming: $\mathrm{FLU}[\mathrm{F}(1,41)=12, p<.05]$ and DMI $[\mathrm{F}(1,41)=6.4, p<.05]$ induced overall changes in swimming. However, FLU alone increased swimming, but not DMI or DF, and there was no DMI $\times$ FLU interaction. Climbing: DMI $[\mathrm{F}(1,44)=23, p<.01]$, but not FLU, produced changes in climbing and there was no DMI $\times$ FLU interaction. Both DMI and DF increased climbing (respectively NK: $p<.01, p<.05$ ), but not FLU alone.

\section{Experiment 2B}

The behavioral effects produced in the FST by co-administrations of idazoxan (IDAZ) with a (desipramine + fluoxetine)-combination (DF) are shown in Figure 2B. Immobility: The two-factor (DF and IDAZ) ANOVAs revealed main effects of $\mathrm{DF}[\mathrm{F}(1,80)=120, p<.01]$ but not IDAZ; There was no DF $\times$ IDAZ interaction. Immobility was decreased for DF as well as for all DF/IDAZ combinations (NK: $p<.01$ for each group). Swimming: DF $[\mathrm{F}(1,80)=23, p<.01]$, but not IDAZ, produced changes in swimming. IDAZ increased DF-induced swimming values $[\mathrm{F}(3,73)=5.1, p<.05]$ in a dosedependent manner (Kruskal-Wallis, $\mathrm{H}(2)=8.2, p<.05$ ). Climbing: $\mathrm{DF}[\mathrm{F}(1,80)=18, p<.01]$, but not IDAZ, produced changes in climbing: Although there was no significant DF $\times$ IDAZ interaction, only DF and DF/IDAZ 0.5 increased climbing (NK: $p<.05, p<.01$ respectively), but not the other DF/IDAZ combinations.

\section{Experiment 3}

The behavioral effects produced in the FST by co-administrations of idazoxan (IDAZ) with milnacipran (MLN) are shown in Figure 3. Immobility: The two-factor (MLN and IDAZ) ANOVAs revealed main effects of both MLN $[\mathrm{F}(1,83)=24, p<.01]$ and IDAZ $[\mathrm{F}(3,83)=$ 


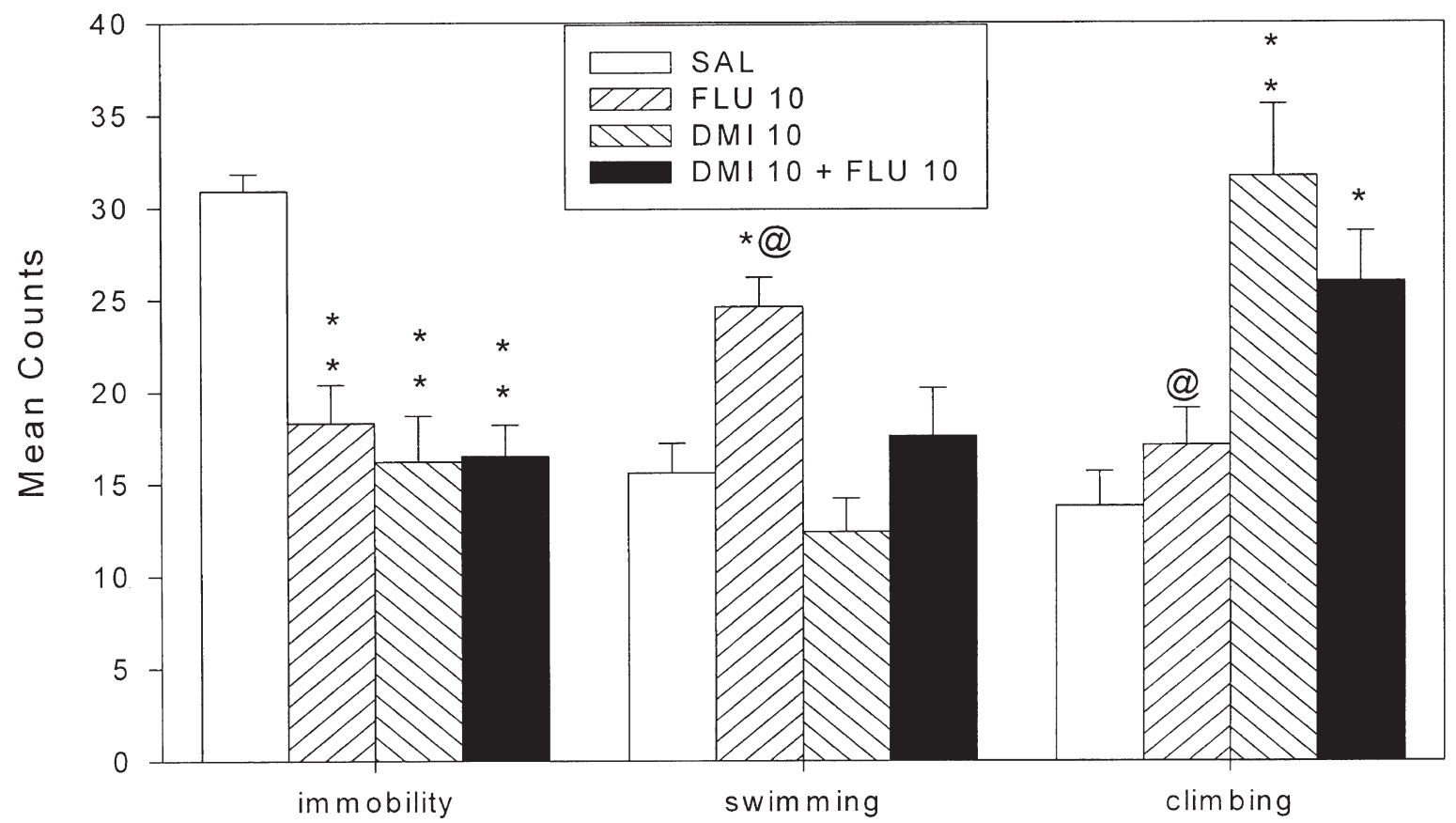

Figure 2A. Behavioral effects produced in the FST by co-administrations of fluoxetine (FLU: $10 \mathrm{mg} / \mathrm{kg}$ ) with desipramine (DMI: $10 \mathrm{mg} / \mathrm{kg})(\mathrm{n}=45)$. Values represent mean $( \pm \mathrm{SEM})$ counts of immobility, swimming and climbing behaviors when sampled every $5 \mathrm{~s}$ during the 5 min test period. Differences in comparison to control group (SAL: $\mathrm{n}=17$ ): ${ }^{*} p<0.05,{ }^{* *} p<$ .01. Differences in comparison to (desipramine + fluoxetine) group [(DMI $10+$ FLU 10): $\mathrm{n}=10]:$ @ $p<.05$. [FLU 10: $\mathrm{n}=8$; DMI 10: $\mathrm{n}=10]$.

8.2, $p<.01$ ], and no MLN $\times$ IDAZ interaction for immobility $(p=.064)$. Immobility-duration was decreased by IDAZ $_{1}$ (NK: $\left.p<.05\right)$, MLN (NK: $\left.p<.05\right)$, MLN/ IDAZ $_{1}(\mathrm{NK}: p<0.01)$ and MLN/IDAZ 10 (NK: $\left.p<.01\right)$. Swimming: No main effect of either MLN or IDAZ were found on swimming. Yet, there was an MLN $\times$ IDAZ interaction $[\mathrm{F}(3,76)=14.8, p<.01]$, which allowed IDAZ to increase MLN-induced swimming-values in a dose-dependent manner (Kruskal-Wallis, $\mathrm{H}(3)=$ 17.3, $p<.01)$. Climbing: Both MLN $[\mathrm{F}(1,83)=8.6, p<$ $.05]$ and $\operatorname{IDAZ}[\mathrm{F}(3,83)=4.6, p<.05]$ had significant main effects on climbing. IDAZ altered MLN-induced increase in climbing $[\mathrm{F}(3,76)=9.5, p<.01]$ in a dosedependent manner (Kruskal-Wallis, $\mathrm{H}(3)=16.1, p<.01$ ).

\section{Experiment 4}

The behavioral effects produced in the FST by co-administrations of 8-OH-DPAT (DPAT) with desipramine (DMI) are shown in Figure 4. Immobility: The two-factor (DMI and DPAT) ANOVAs revealed a main effect of DMI [F(1, $80)=57, p<.01]$ but not DPAT. There was no DMI $\times$ DPAT interaction for immobility. DMI, as well as all DMI/DPAT combinations, reduced immobility-duration (NK: $p<.01$ for each group). Swimming: DMI $[\mathrm{F}(1,80)=$ $38, p<.01]$, but not DPAT, produced changes in swimming, and there was no significant DMI $\times$ DPAT interaction $[\mathrm{F}(3,73)=2.7, p>$.05]. All DMI/DPAT combinations decreased swimming behavior (NK: $p<.05$ for each group). Climbing: Both DMI $[\mathrm{F}(1,80)=115, p<.01]$ and DPAT $[F(3,80)=4.2, p<.05]$ produced changes in climbing. DPAT dose-dependently increased DMI-induced values for climbing (Kruskal-Wallis, $\mathrm{H}(3)=9.3, p<.05$ ).

\section{Experiment 5}

The effects produced in the FST by co-administrations of 8-OH-DPAT (DPAT) with fluoxetine (FLU) are shown in Figure 5. Immobility: $\operatorname{FLU}[\mathrm{F}(1,81)=22, p<.01]$, but not DPAT, induced changes in immobility, and there was no FLU $\times$ DPAT interactions for immobility. FLU (NK: $p<.05), \mathrm{FLU} \mathrm{DPAT}_{0.5}$ (NK: $\left.p<.05\right), \mathrm{FLU} / \mathrm{DPAT}_{1}$ (NK: $p<.01)$ significantly decreased immobility. Swimming: FLU $[\mathrm{F}(1,81)=17, p<.01]$, but not DPAT, induced changes in swimming. Albeit there was no significant FLU $\times$ DPAT interactions, the FLU induced increase in swimming (NK: $p<.01$ ) was blocked by $\mathrm{DPAT}_{1}(\mathrm{NK}: p<0.05)$. Climbing: DPAT $[\mathrm{F}(1,81)=6, p<$ $.01]$, but not FLU, induced changes in climbing. DPAT increased FLU-induced values for climbing in a dosedependent manner (Kruskal-Wallis, $\mathrm{H}(3)=9.9, p<.05$ ).

\section{Locomotor Activity}

The effects on locomotor activity of treatments that produced significant effects in the FST are shown on Table 


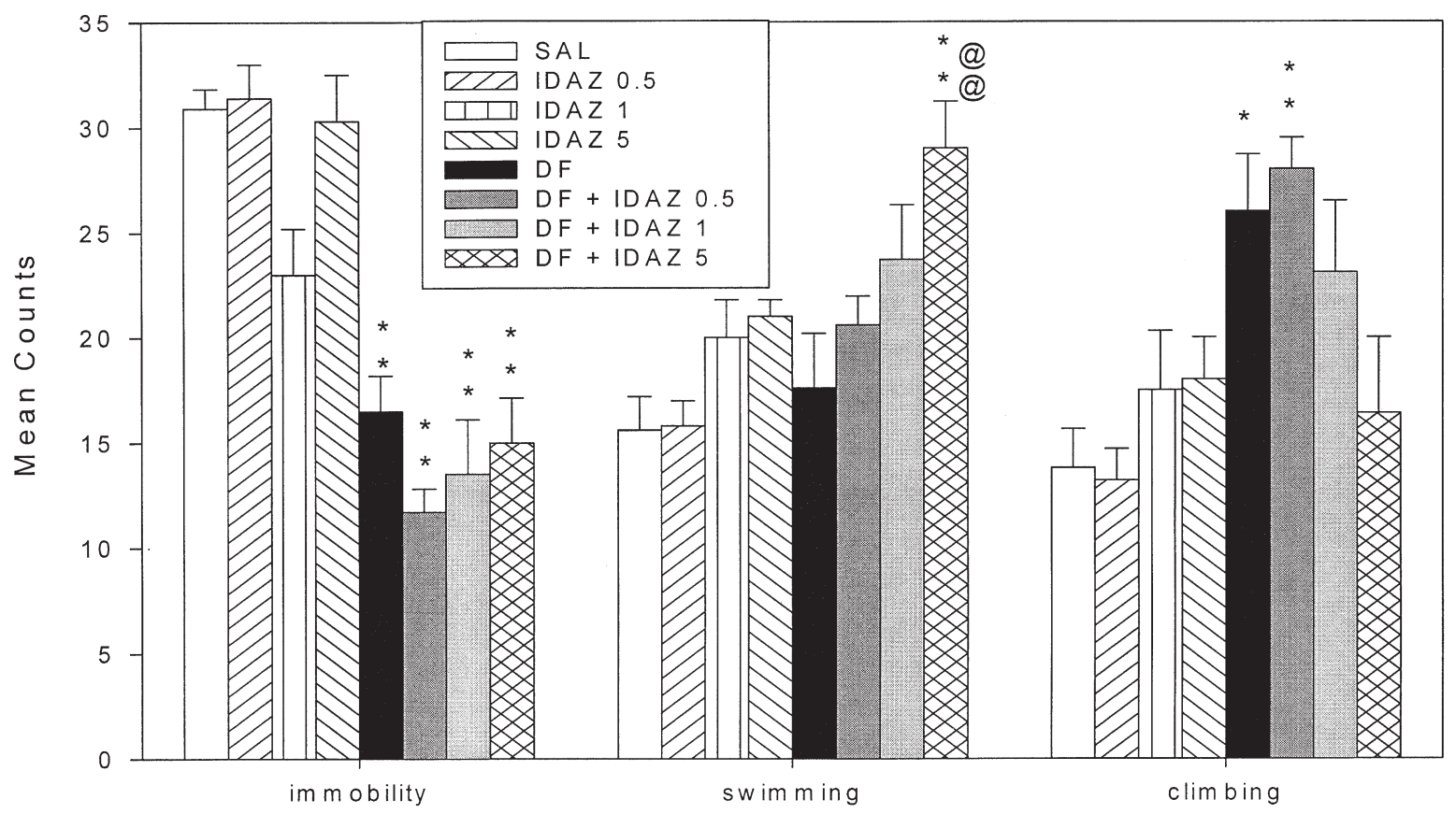

Figure 2B. Behavioral effects produced in the FST by co-administrations of idazoxan (IDAZ: 0.5, 1, $5 \mathrm{mg} / \mathrm{kg}$ ) with a (desipramine + fluoxetine)-combination (DF: $10 / 10 \mathrm{mg} / \mathrm{kg})(\mathrm{n}=81)$. Values represent mean $( \pm \mathrm{SEM})$ counts of immobility, swimming and climbing behaviors when sampled every $5 \mathrm{~s}$ during the $5 \mathrm{~min}$ test period. Differences in comparison to control group (SAL: $\mathrm{n}=17$ ): ${ }^{*} p<.05,{ }^{* *} p<.01$. Differences in comparison to (desipramine + fluoxetine) group (DF: $\left.\mathrm{n}=10\right)$ : @@ $p<.01$. [IDAZ 0.5: $\mathrm{n}=11$; IDAZ 1: $\mathrm{n}=8$; IDAZ 5: $\mathrm{n}=10 ;(\mathrm{DF}+\operatorname{IDAZ} 0.5): \mathrm{n}=10 ;(\mathrm{DF}+\operatorname{IDAZ} 1): \mathrm{n}=10 ;(\mathrm{DF}+\mathrm{IDAZ} 5): \mathrm{n}=5$ ].

1. Excepted for 8-OH-DPAT $1 \mathrm{mg} / \mathrm{kg}$, which did not significantly differ from control rats, all treatments substantially decreased general locomotor activity $[\mathrm{F}(6,42)=$ 12.56, $p<.001]$. Locomotor activity induced by FLU, DMI, DMI+FLU, and MLN treatments were not replicated in this study, as they previously significantly decreased it in the same experimental conditions and at same dosage (Rénéric \& Lucki, 1998). The (FLU + DMI + IDAZ) coadministration produced the greatest decrease of locomotor activity in this study.

\section{DISCUSSION}

The purpose of this study was to examine the effects produced in the FST by the $\alpha_{2}$-receptor antagonist idazoxan and by the $5-\mathrm{HT}_{1 \mathrm{~A}}$-receptor agonist 8 -OH-DPAT, alone and in combination with antidepressant treatments which inhibit the reuptake of either 5-HT, NA, or both 5-HT and NA. Most of the treatments that were examined decreased locomotor-activity (Table 1). Therefore, the decrease in immobility-duration, or the increase in swimming or climbing behaviors, induced in the FST by these treatments, were not secondary to a non-specific increase in locomotor-activity.

In this study, $1 \mathrm{mg} / \mathrm{kg}$ idazoxan decreased immobility-duration (Figures 1 and 3), supporting the clinical antidepressant efficacy of this drug (Osman et al. 1989;
Pinder and Sitsen 1987) and of other $\alpha_{2}$-receptor antagonists such as mirtazapine (de Boer 1995, 1996) or mianserin (Bremner 1995; Claghorn and Lesem 1995). The concurrent increase in swimming behavior (Figure 3) suggests that the idazoxan-antidepressant-like effect may be mediated through the enhancement of 5-HT-transmission, which is consistent with the drug increasing dorsal-raphe neuronal firing (Garratt et al. 1991; Routledge and Marsden 1987).

Yet, lower and higher doses of idazoxan $(0.5,5,10 \mathrm{mg} /$ $\mathrm{kg}$ IP) did not produce antidepressant-like effects in our experiments, as was similarly the case in previous studies (Cervo et al. 1990). Since idazoxan displays a much higher affinity for $\alpha_{2}$-auto than $\alpha_{2}$-hetero-receptors located on 5-HT-nerve terminals, the idazoxan-induced noradrenergic outflow (de Boer et al. 1996; Tao and Hjorth 1992) may negatively modulate the release of 5-HT (Preziosi et al. 1989), and thus prevent any behavioral effect in the FST.

In a more constant manner, which contrasts with the varying effects produced by the drug acting alone, idazoxan dose-dependently antagonized desipramineinduced both decrease in immobility-duration and increase in climbing behavior (Figure 1). Our data confirm previous results in the FST (Cervo et al. 1990; Kitada et al. 1983), and contrast with microdialysis data suggesting that systemic idazoxan $(1 \mathrm{mg} / \mathrm{kg})$ boosts the desipramine-induced increase of NA-release (Thomas and Holman 1991). 


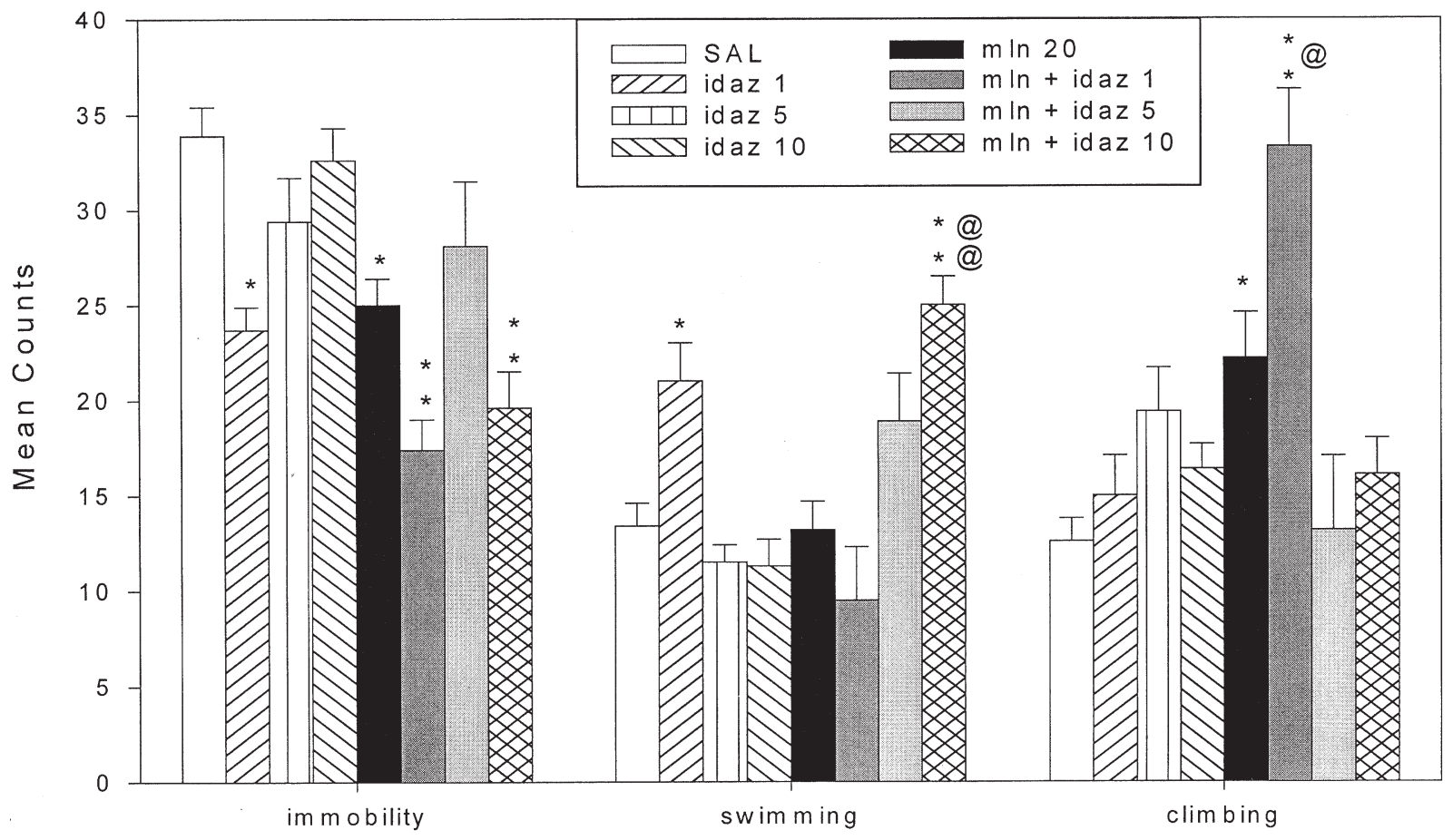

Figure 3. Behavioral effects produced in the FST by co-administrations of idazoxan (IDAZ: 1, 5, $10 \mathrm{mg} / \mathrm{kg}$ ) with milnacipran (MLN: $20 \mathrm{mg} / \mathrm{kg})(\mathrm{n}=84)$. Values represent mean $( \pm \mathrm{SEM})$ counts of immobility, swimming, and climbing behaviors when sampled every $5 \mathrm{~s}$ during the 5 min test period. Differences in comparison to control group $(\mathrm{SAL}: \mathrm{n}=16):{ }^{*} p<.05,{ }^{* *} p<$ .01. Differences in comparison to milnacipran group $(\mathrm{mln} 20: \mathrm{n}=11)$ : @ $p<.05$, @@ $p<.01$. [IDAZ 1: $\mathrm{n}=10$; IDAZ 5: $\mathrm{n}=11$; IDAZ 10: $\mathrm{n}=7 ;(\operatorname{mln}+\operatorname{idaz} 1): \mathrm{n}=11 ;(\operatorname{mln}+\operatorname{idaz} 5): \mathrm{n}=11 ;(\operatorname{mln}+\operatorname{idaz} 10): \mathrm{n}=7]$.

In order to study $\alpha_{2}$-heteroreceptor-mediated inhibiting interactions on the 5-HT-system, we examined the changes induced by idazoxan on the behavioral effects produced by dual 5-HT/NA reuptake inhibition. The (desipramine + fluoxetine) combination (Figure 2A) or milnacipran (Figure 3) increased climbing behavior solely, just as NRIs do, thus replicating previous data (Rénéric and Lucki 1998). Interestingly, in desipramine + fluoxetine-treated rats, idazoxan concurrently blocked climbing behavior, and alleviated the inhibition of 5-HT-mediated behavior, thereby resulting in a dosedependent increase in swimming (Figure 2B). This suggests that idazoxan preferentially antagonized $\alpha_{2}$-heteroreceptors, which nevertheless contrasts with a reported 250-fold greater affinity for $\alpha_{2}$-auto than for $\alpha_{2}$-hetero receptors (Preziosi et al. 1989). The idazoxaninduced decrease in climbing might be secondary to the $\alpha_{2}$-heteroreceptors-blockade-induced increase in 5-HT-release, that in return, interacts negatively with NA-cells firing (Aston-Jones et al. 1991a,b). It is, however, interesting to note that the co-administration of desipramine + fluoxetine with $1 \mathrm{mg} / \mathrm{kg}$ idazoxan resulted in a slightly further reduction in immobilityduration as well as in a concurrent increase in both swimming and climbing behaviors, thereby suggesting an overall increased efficacy. Consequently, the selection of an adequate dose of idazoxan for the augmenta- tion of antidepressant drugs may be an important factor, since it can bypass inhibiting interactions on the 5-HT-system without altering NA-transmission. This result could present some advantages regarding efficacy in medical practice, as was recently suggested by the augmentation of fluoxetine by way of the $\alpha_{2}$-antagonist antidepressant mianserin (Maes et al. 1999).

Similar data were obtained when idazoxan was combined with the SNRI milnacipran, a clinically effective new antidepressant (Artigas 1995b), devoid of any activity at post-synaptic receptors (Briley et al. 1996; Moret et al. 1985). Idazoxan dose-dependently permitted milnacipran to increase swimming behavior, thereby allowing the 5-HT pharmacological properties of milnacipran to be expressed in the test (Figure 3). Surprisingly, a $1 \mathrm{mg} / \mathrm{kg}$ dose of idazoxan potentiated milnacipran-induced climbing. This result contrasts with this dose and higher doses antagonizing the climbing effects produced respectively by desipramine (Figure 1) and milnacipran, probably by way of the inhibiting effects of increased 5-HT-transmission on NA-cells activity (Aston-Jones et al. 1991a,b).

In this study, idazoxan prevented the NA-mediated inhibition of the 5-HT-system, thus supporting the involvement of the $\alpha_{2}$-heteroreceptors in this phenomenon, as formerly suggested in other studies (Mongeau et al. 1997). It is therefore possible that $\alpha_{2}$-receptor an- 


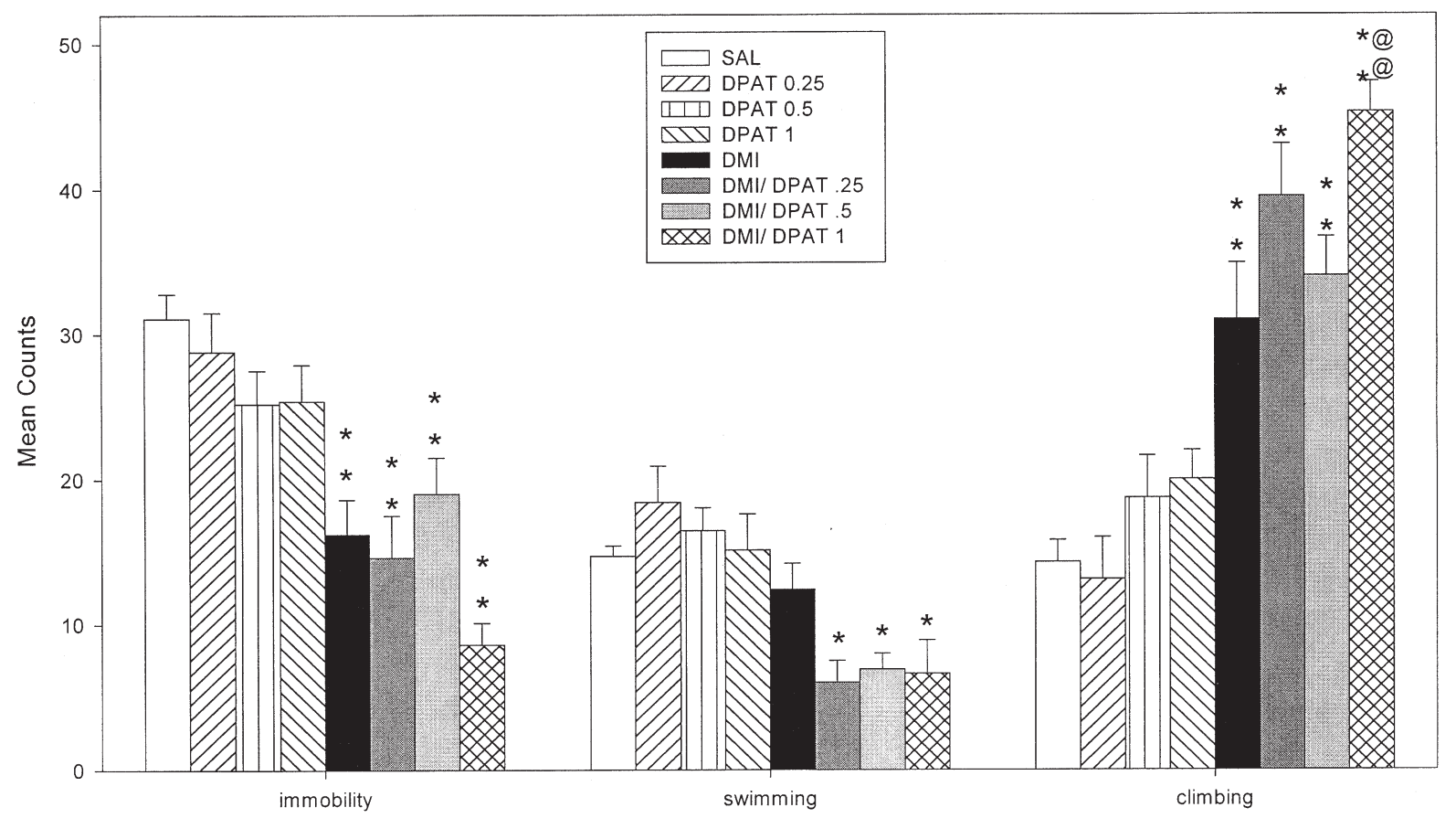

Figure 4. Behavioral effects produced in the FST by co-administrations of 8-OH-DPAT (DPAT: 0.25, 0.5, $1 \mathrm{mg} / \mathrm{kg}$ ) with desipramine (DMI: $10 \mathrm{mg} / \mathrm{kg})(\mathrm{n}=81)$. Values represent mean $( \pm \mathrm{SEM})$ counts of immobility, swimming, and climbing behaviors when sampled every $5 \mathrm{~s}$ during the 5 min test period. Differences in comparison to control group (SAL: $\mathrm{n}=13$ ): ${ }^{*} p<.05,{ }^{* *} p<.01$. Differences in comparison to desipramine group (DMI: $\mathrm{n}=10$ ): @@ $p<0.01$. [DPAT 0.25: $\mathrm{n}=11 ;$ DPAT 0.5: $\mathrm{n}=11 ;$ DPAT 1: $\mathrm{n}=11$; (DMI/DPAT .25): $\mathrm{n}=8$; (DMI/DPAT .5): $\mathrm{n}=9$; (DMI/DPAT 1): $\mathrm{n}=8$ ].

tagonists, which have already proven to be clinically effective antidepressants in the form of mirtazapine (Bremner 1995; Claghorn and Lesem 1995), may be useful adjuncts to classical antidepressant drugs in augmentation strategies (Maes et al. 1999).

In our experiments, none of the doses of the $5-\mathrm{HT}_{1 \mathrm{~A}^{-}}$ agonist 8-OH-DPAT significantly decreased immobility-duration nor produced an SSRI-like increase in swimming (Detke et al. 1995a; Lucki et al. 1994; Kitamura and Nagatani 1996), but they did tend to increase climbing behavior (Figure 4). This behavioral pattern of response is consistent with 8-OH-DPAT decreasing 5-HTrelease, as well as with increasing NA-neuronal firing and NA-release (Casanovas et al. 1997; Kreiss and Lucki 1997; Piercey et al. 1994).

More clear-cut effects were produced when 8-OH-DPAT was combined with either selective NA or 5-HT antidepressants. 8-OH-DPAT boosted the antiimmobility effects produced by the NRI desipramine, and dose-dependently potentiated the drug induced climbing behavior (Figure 4). These results are consistent with $5-\mathrm{HT}_{1 \mathrm{~A}}$-receptor antagonists preventing the antidepressantlike effects of desipramine in the FST (Detke et al. 1995c).

Similarly, 8-OH-DPAT tended to potentiate the antiimmobility effects produced by the SSRI fluoxetine (figure 5). This is in agreement with the $5-\mathrm{HT}_{1 \mathrm{~A}}$-agonist buspirone augmenting SSRIs' efficacy in the FST (Arti- gas et al. 1996; Redrobe and Bourin 1998, 1999), and also in depressed patients (Bouwer and Stein 1997; Dimitriou and Dimitriou 1998; Jacobsen 1991; Joffe and Schuller 1993). Interestingly, these data suggest that the 8-OH-DPAT-induced effects in the FST were preferentially mediated through auto rather than hetero $5-\mathrm{HT}_{1 \mathrm{~A}^{-}}$ receptors. Furthermore, 8-OH-DPAT dose-dependently increased climbing behavior to significantly higher values than those produced on its own (Figure 5).

Overall, these data suggest that the 8-OH-DPATinduced effects in the FST were preferentially mediated through auto rather than hetero $5-\mathrm{HT}_{1 \mathrm{~A}}$-receptors. Indeed, the administration of 8-OH-DPAT or buspirone in the dorsal-raphe nucleus produces antidepressantlike effects in the test (Cervo et al. 1988b) and the lesion of 5-HT-neurons prevents 8-OH-DPAT from producing anti-immobility effects in the FST (Cervo et al. 1988a). The stimulation of somatodendritic $5-\mathrm{HT}_{1 \mathrm{~A}}$-receptors may primarily decrease 5-HT-transmission, thereby preventing swimming, and may secondarily favor NAtransmission and climbing behavior (Figures 4 and 5) by alleviating 5-HT-mediated inhibition of NA-cells firing (Aston-Jones et al. 1991a,b). However, enhancement of climbing may also reflect the $\alpha_{2}$-receptors-antagonist properties of 8-OH-DPAT (Lucki et al. 1994), either directly on the NA system, or indirectly through the stimulation of DA-neurotransmission (Tanda et al. 1994 ; 


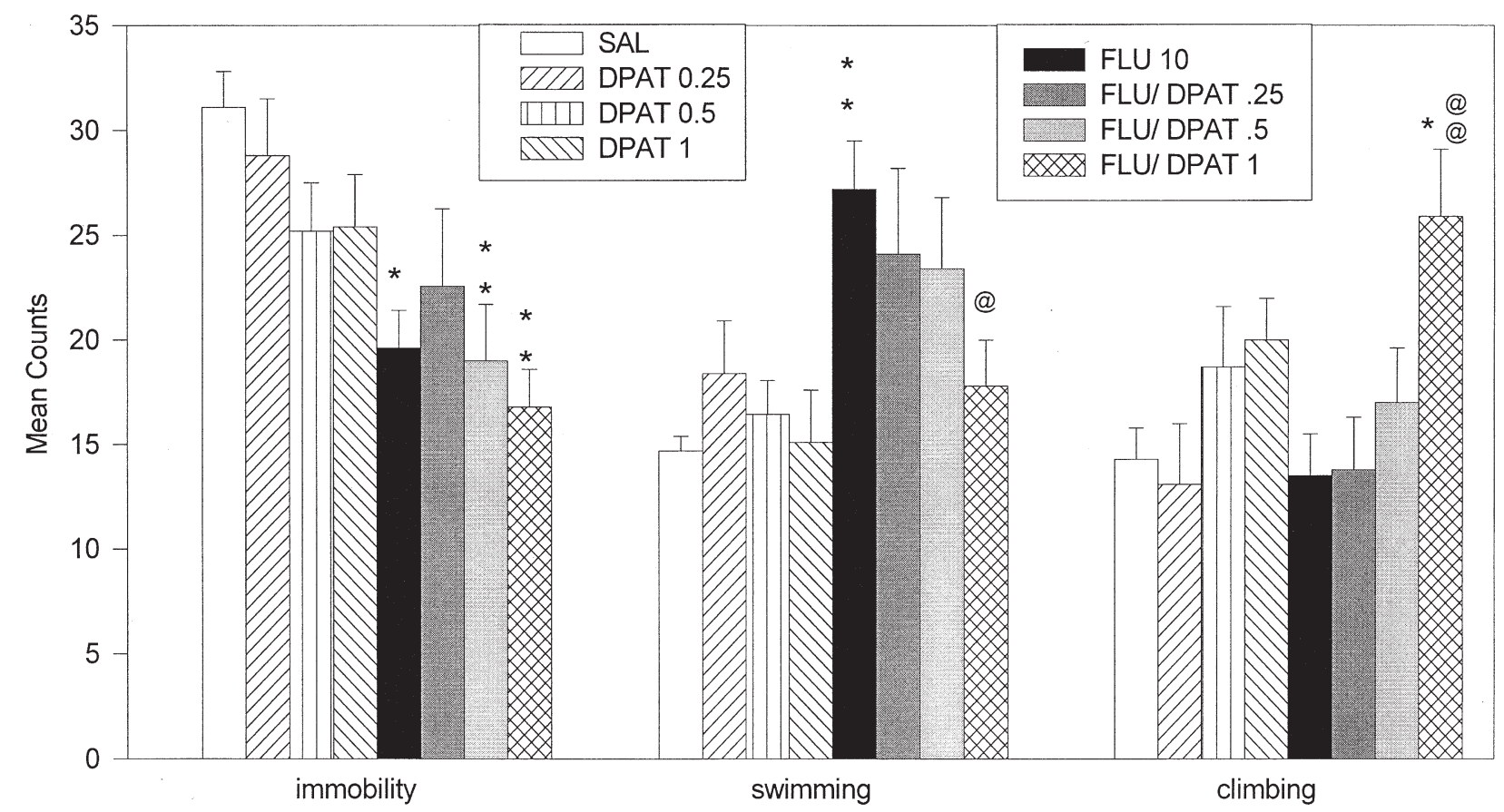

Figure 5. Behavioral effects produced in the FST by co-administrations of 8-OH-DPAT (DPAT: 0.25, 0.5, $1 \mathrm{mg} / \mathrm{kg}$ ) with fluoxetine (FLU: $10 \mathrm{mg} / \mathrm{kg})(\mathrm{n}=82)$. Values represent mean $( \pm$ SEM) counts of immobility, swimming and climbing behaviors when sampled every $5 \mathrm{~s}$ during the 5 min test period. Differences in comparison to control group (SAL: $\mathrm{n}=13):{ }^{*} p<.05,{ }^{* *} p<$ .01. Differences in comparison to fluoxetine group (FLU 10: $\mathrm{n}=11)$ : @ $p<.05$, @@ $p<.01$. [DPAT 0.25: $\mathrm{n}=11$; DPAT 0.5: $\mathrm{n}=11$; DPAT 1: $\mathrm{n}=11 ;($ FLU/DPAT .25): $\mathrm{n}=7$; (FLU/DPAT .5): $\mathrm{n}=9$; (FLU/DPAT 1): $\mathrm{n}=9]$.

Hertel et al. 1999). Indeed, DA antidepressants do increase climbing behavior in the FST (Hemby et al. 1997; Rénéric and Lucki 1998).

The data from the literature, however, are rather conflicting with regard to the site and mechanism of action of 5- $\mathrm{HT}_{1 \mathrm{~A}}$-receptor-agonists. For example, a post-synaptic site of action was suggested for 8-OH-DPAT, since PCPA-induced 5-HT-depletion did not prevent the effects of the drug in the FST (Wieland and Lucki 1990).

Table 1. Total Locomotor Activity of Rats Having Been Administered Drugs

\begin{tabular}{lccc}
\hline Drugs & $\begin{array}{c}\text { Dose } \\
\mathbf{( m g / k g )}\end{array}$ & $\begin{array}{c}\text { Locomotor } \\
\text { Activity }\end{array}$ \\
\hline Vehicle & - & 8 & $997 \pm 100$ \\
DPAT & 1 & 7 & $1024 \pm 84$ \\
DPAT + fluoxetine & $1 / 10$ & 7 & $583 \pm 95^{* *}$ \\
DPAT + desipramine & $1 / 10$ & 7 & $388 \pm 77^{* *}$ \\
Idazoxan + desipramine + fluoxetine & $5 / 10 / 10$ & 6 & $169 \pm 38^{* *}$ \\
Idazoxan + milnacipran & $1 / 20$ & 7 & $601 \pm 95^{*}$ \\
Idazoxan + milnacipran & $10 / 20$ & 7 & $582 \pm 75^{* *}$ \\
\hline
\end{tabular}

Values represent mean crosses \pm 1 SEM in a $1 \mathrm{hr}$ activity session. The treatment procedures were similar to that used in the FST. Data were analyzed with a one-way ANOVA, followed by Dunnett's test for comparison to control group: differences with saline rats: ${ }^{*} p<.05,{ }^{* *} p<.01$; values for fluoxetine, desipramine, and milnacipran were not replicated in this study as they were previously shown to decrease locomotor activity at the same dosage and under similar experimental conditions (Rénéric and Lucki, 1998).
Also, buspirone was found to increase immobility (Kitamura and Nagatani 1996) and to block the anti-immobility effects of fluoxetine in the test (Da-Rocha et al. 1997). Buspirone, however, generates an effective $\alpha_{2}$-antagonist metabolite (1-PP) that may account for the discrepancies between 8-OH-DPAT and buspirone induced effects.

Other conflicting data exist concerning the role of $5-\mathrm{HT}_{1 \mathrm{~A}}$-receptors. Indeed, agonists and antagonists at $5-\mathrm{HT}_{1 \mathrm{~A}}$-receptors can produce similar effects, both preclinically and clinically. Pindolol, a $\beta$-blocker with $5-\mathrm{HT}_{1 \mathrm{~A}}$-antagonism properties, was thus shown to increase SSRIs' anti-imobility effects in the mouse FST (Redrobe and Bourin 1999), and could augment their efficacy in refractory depressed patients (Artigas 1995a; Bordet et al. 1998; Maes et al. 1996; Tome et al. 1997; Zanardi et al. 1998). The pattern of response to antidepressant treatments acting through the modulation of $5-\mathrm{HT}_{1 \mathrm{~A}}$-receptors may therefore depend on a few factors, such as the subtype of depressed patients, and the brain structures which are specifically involved (Borsini 1994; De Vry 1995). For example, the inhibitory effects of 8-OH-DPAT on 5-HT-neurons firing would involve a feedback loop activated by post-synaptic $5-\mathrm{HT}_{1 \mathrm{~A}}$-receptors (Ceci et al. 1994; Hajos et al. 1999).

The variability of the responses to $5-\mathrm{HT}_{1 \mathrm{~A}}$-receptoragonists may also depend on the dose administered. Indeed, such a phenomenon occurs with the $\alpha_{2}$-receptor agonist clonidine, which stimulates $\alpha_{2}$-auto and $\alpha_{2}$-heter- 
oreceptors at respectively low and high doses (Mongeau et al. 1993). Similarly, pindolol either boosted or blocked fluoxetine-induced swimming in the rat FST, supposedly through the blockade of respectively pre and post synaptic 5- $\mathrm{HT}_{1 \mathrm{~A}}$-receptors (Detke et al. 1996). A biphasic pattern of response can thus be hypothesized for 8-OH-DPAT, with low-doses preferentially stimulating $5-\mathrm{HT}_{1 \mathrm{~A}}$-autoreceptors and decreasing 5-HT-transmission, whereas higher doses may recruit $5-\mathrm{HT}_{1 \mathrm{~A}}$-heteroreceptors and mediate the increase in climbing behavior. A greater range of 8-OH-DPAT-doses should thus be assessed in the FST, alone and in combination with SSRIs, in order to examine this hypothesis. It is therefore difficult to establish the specific contribution of the different $5-\mathrm{HT}_{1 \mathrm{~A}^{-}}$ receptor subtypes to an integrated behavioral response, as measured in the FST or in depressed humans.

In this study, neither subacute idazoxan nor 8-OH-DPAT produced significant effects per se in the FST. It is probable that long-term treatment would have produced a more clear-cut pattern of response, thus allowing reasonable and coherent suggestions on their respective mode of action. Nevertheless, the effects of idazoxan and 8-OH-DPAT appeared to be more tangible when they were co-administered with antidepressant drugs, thereby suggesting that the behavioral effects of drugs acting directly on modulatory receptors are the most clearly expressed when the neurotransmission-system(s) on which they act is (are) simultaneously activated. Overall, this study confirms the fundamental involvement of both auto and hetero-receptors of the NA and 5-HT systems in the treatment of depression, and suggests that the research and elaboration of augmentation strategies should take into account the regulatory mechanisms and/or interactions mediated through these receptors. Although it is difficult to establish the specific contribution of the different receptor subtypes to an integrated behavioral response, as measured in the FST, this model appears to be an interesting tool for the global assessment of antidepressant treatment efficacy and mechanisms of action.

\section{ACKNOWLEDGMENTS}

This work was supported by grants from the University of Bordeaux 2, the Centre National de le Recherche Scientifique (CNRS), the Conseil Regional d'Aquitaine. The authors would like to thank Irwin Lucki for his generous help in providing constructive suggestions, as well as Joël D. Swendsen for his help in the statistical analysis. The authors would also like to thank Steve Detofsky for proofreading and correcting the manuscript.

\section{REFERENCES}

Artigas F (1995a): Pindolol, 5-hydroxytryptamine, and antidepressant augmentation [letter; comment]. Arch Gen Psychiatry 52:969-971
Artigas F (1995b): Selective serotonin noradrenaline reuptake inhibitors (SNRIs): pharmacology and therapeutic potential in the treatment of depressive disorders. CNS Drugs 4:79-89

Artigas F, Romero L, de Montigny C, Blier P (1996): Acceleration of the effect of selected antidepressant drugs in major depression by 5-HT1A antagonists. Trends Neurosci 19:378-383

Aston-Jones G, Akaoka H, Charlety P, Chouvet G (1991a): Serotonin selectively attenuates glutamate-evoked activation of noradrenergic locus coeruleus neurons. J Neurosci 11:760-769

Aston-Jones G, Shipley MT, Chouvet G, Ennis M, van Bockstaele E, Pieribone V, Shiekhattar R, Akaoka H, Drolet G, Astier B, et al. (1991b): Afferent regulation of locus coeruleus neurons: anatomy, physiology and pharmacology. Prog Brain Res 88:47-75

Blier P, de Montigny C, Chaput Y (1990): A role for the serotonin system in the mechanism of action of antidepressant treatments: Preclinical evidence. J Clin Psychiatry 51(suppl):14-20

Bordet R, Thomas P, Dupuis B (1998): Effect of pindolol on onset of action of paroxetine in the treatment of major depression: intermediate analysis of a double-blind, placebo- controlled trial. Reseau de Recherche et d'Experimentation Psychopharmacologique. Am J Psychiatry 155:1346-1351

Borsini F (1994): Balance between cortical 5-HT1A and 5-HT2 receptor function: hypothesis for a faster antidepressant action. Pharmacol Res 30:1-11

Borsini F (1995): Role of the serotonergic system in the forced swimming test. Neurosci Biobehav Rev 19:377-395

Borsini F, Meli A (1988): Is the forced swimming test a suitable model for revealing antidepressant activity? Psychopharmacology (Berl) 94:147-160

Bouwer C, Stein DJ (1997): Buspirone is an effective augmenting agent of serotonin selective re- uptake inhibitors in severe treatment-refractory depression. S Afr Med J 87:534-540

Bremner JD (1995): A double-blind comparison of Org 3770, amitriptyline, and placebo in major depression. J Clin Psychiatry 56:519-525

Briley M, Prost JF, Moret C (1996): Preclinical pharmacology of milnacipran. Int Clin Psychopharmacol 11 Suppl 4:9-14

Caldecott Hazard S, Morgan DG, DeLeon Jones F, Overstreet DH, Janowsky D (1991): Clinical and biochemical aspects of depressive disorders: II. Transmitter/receptor theories. Synapse 9:251-301

Casanovas JM, Lesourd M, Artigas F (1997): The effect of the selective 5-HT1A agonists alnespirone (S-20499) and 8- OH-DPAT on extracellular 5-hydroxytryptamine in different regions of rat brain. Br J Pharmacol 122:733-741

Ceci A, Baschirotto A, Borsini F (1994): The inhibitory effect of 8-OH-DPAT on the firing activity of dorsal raphe serotoninergic neurons in rats is attenuated by lesion of the frontal cortex. Neuropharmacology 33:709-713

Cervo L, Grignaschi G, Samanin R (1988a): 8-Hydroxy-2-(di$\mathrm{n}$-propylamino)tetralin, a selective serotonin $1 \mathrm{~A}$ receptor agonist, reduces the immobility of rats in the forced swimming test by acting on the nucleus raphe dorsalis. Eur J Pharmacol 158:53-59 
Cervo L, Grignaschi G, Samanin R (1988b): Different effects of intracerebral and systemic administration of buspirone in the forced swimming test: Involvement of a metabolite. Life Sci 43:2095-2102

Cervo L, Grignaschi G, Samanin R (1990): Alpha 2-adrenoceptor blockade prevents the effect of desipramine in the forced swimming test. Eur J Pharmacol 175:301-307

Claghorn JL, Lesem MD (1995): A double-blind placebo-controlled study of Org 3770 in depressed outpatients. J Affect Disord 34:165-171

Clement HW, Gemsa D, Wesemann W (1992): The effect of adrenergic drugs on serotonin metabolism in the nucleus raphe dorsalis of the rat, studied by in vivo voltammetry. Eur J Pharmacol 217:43-48

Da-Rocha MA, Jr., Puech AJ, Thiebot MH (1997): Influence of anxiolytic drugs on the effects of specific serotonin reuptake inhibitors in the forced swimming test in mice. J Psychopharmacol 11:211-218

de Boer T (1995): The effects of mirtazapine on central noradrenergic and serotonergic neurotransmission. Int Clin Psychopharmacol 10(suppl 4):19-23

de Boer T (1996): The pharmacologic profile of mirtazapine. J Clin Psychiatry 57(suppl 4):19-25

de Boer TH, Nefkens F, van Helvoirt A, van Delft AM (1996): Differences in modulation of noradrenergic and serotonergic transmission by the alpha-2 adrenoceptor antagonists, mirtazapine, mianserin and idazoxan. J Pharmacol Exp Ther 277:852-860

De Vry J (1995): 5-HT1A receptor agonists: recent developments and controversial issues. mechanism of antidepressant action: effects of catecholamine depletion on mood of patients treated with antidepressants. Psychopharmacol Bull 29:389-396

Detke MJ, Kirby L, Lucki I (1995a): Serotoninergic mechanisms involved in the effects of fluoxetine in the rat forced swimming test. Soc Neurosci Abs 21:976

Detke MJ, Rénéric JP, Lucki I (1996): Pindolol boosts or blocks fluoxetine in the rat forced swimming test (FST) depending on the fluoxetine dose. Soc Neurosci Abstr 22:185

Detke MJ, Rickels M, Lucki I (1995b): Active behaviors in the rat forced swimming test differentially produced by serotonergic and noradrenergic antidepressants. Psychopharmacology (Berl) 121:66-72

Detke MJ, Wieland S, Lucki I (1995c): Blockade of the antidepressant-like effects of 8-OH-DPAT, buspirone and desipramine in the rat forced swim test by 5HT1A receptor antagonists. Psychopharmacology (Berl) 119: $47-54$

Dimitriou EC, Dimitriou CE (1998): Buspirone augmentation of antidepressant therapy. J Clin Psychopharmacol 18:465-469

Doxey JC, Roach AG, Smith CF (1983): Studies on RX 781094: a selective, potent and specific antagonist of alpha 2-adrenoceptors. Br J Pharmacol 78:489-505

Garratt J, Crespi F, Mason R, Marsden C (1991): Effects of idazoxan on dorsal raphe 5-hydroxytryptamine neuronal function. Eur J Pharmacol 193:87-93

Hajos M, Hajos-Korcsok E, Sharp T (1999): Role of the medial prefrontal cortex in 5-HT1A receptor-induced inhibition of 5-HT neuronal activity in the rat. Br J Pharmacol 126:1741-1750

Hemby SE, Lucki I, Gatto G, Singh A, Thornley C, Matasi J, Kong N, Smith JE, Davies HM, Dworkin SI (1997): Potential antidepressant effects of novel tropane compounds, selective for serotonin or dopamine transporters. J Pharmacol Exp Ther 282:727-733

Heninger GR, Delgado PL, Charney DS (1996): The revised monoamine theory of depression: a modulatory role for monoamines, based on new findings from monoamine depletion experiments in humans. Pharmacopsychiatry 29:2-11

Hertel P, Nomikos GG, Svensson TH (1999): Idazoxan preferentially increases dopamine output in the rat medial prefrontal cortex at the nerve terminal level. Eur J Pharmacol 371:153-158

Jacobsen FM (1991): Possible augmentation of antidepressant response by buspirone [see comments]. J Clin Psychiatry 52:217-220

Joffe RT, Schuller DR (1993): An open study of buspirone augmentation of serotonin reuptake inhibitors in refractory depression. J Clin Psychiatry 54:269-271

Katz MM, Maas JW, Frazer A, Koslow SH, Bowden CL, Berman N, Swann AC, Stokes PE (1994): Drug-induced actions on brain neurotransmitter systems and changes in the behaviors and emotions of depressed patients. Neuropsychopharmacology 11:89-100

Kitada Y, Miyauchi T, Kosasa T, Satoh S (1983): Further studies on the suppressing effect of isoproterenol on the immobility-reducing action of desipramine in the forced swimming test. Jpn J Pharmacol 33:867-873

Kitamura Y, Nagatani T (1996): Buspirone enhances immobility in the forced swim test in mice. Pharmacol Biochem Behav 55:445-451

Kreiss DS, Lucki I (1997): Chronic administration of the 5-HT1A receptor agonist 8-OH-DPAT differentially desensitizes 5-HT1A autoreceptors of the dorsal and median raphe nuclei. Synapse 25:107-116

Lucki I (1997): The forced swimming test as a model for core and component behavioral effects of antidepressant drugs. Behav Pharmacol 8:523-532

Lucki I, Singh A, Kreiss DS (1994): Antidepressant-like behavioral effects of serotonin receptor agonists. Neurosci Biobehav Rev 18:85-95

Maes M, Libbrecht I, van Hunsel F, Campens D, Meltzer HY (1999): Pindolol and mianserin augment the antidepressant activity of fluoxetine in hospitalized major depressed patients, including those with treatment resistance. J Clin Psychopharmacol 19:177-82

Maes M, Vandoolaeghe E, Desnyder R (1996): Efficacy of treatment with trazodone in combination with pindolol or fluoxetine in major depression. J Affect Disord 41:201-210

Middlemiss DN, Fozard JR (1983): 8-Hydroxy-2-(di-n-propylamino)-tetralin discriminates between subtypes of the 5-HT1 recognition site. Eur J Pharmacol 90:151-153

Mongeau R, Blier P, de Montigny C (1993): In vivo electrophysiological evidence for tonic activation by endogenous noradrenaline of alpha 2-adrenoceptors on 5- hydroxytryptamine terminals in the rat hippocampus. Naunyn Schmiedebergs Arch Pharmacol 347:266-272 
Mongeau R, Blier P, de Montigny C (1997): The serotonergic and noradrenergic systems of the hippocampus: their interactions and the effects of antidepressant treatments. Brain Res Brain Res Rev 23:145-195

Moret C, Charveron M, Findberg JP, Couzinier JP, Briley M (1985): Biochemical profile of midalcipran (F 2207), 1-phenyl-diethyl-aminocarbonyl-2-aminomethyl-cyclopropane (Z) hydrochloride, a potential fourth generation antidepressant drug. Neuropharmacology 24:1211-1219

Nelson JC, Mazure CM, Bowers MB, Jr., Jatlow PI (1991): A preliminary, open study of the combination of fluoxetine and desipramine for rapid treatment of major depression [see comments]. Arch Gen Psychiatry 48:303-307

Osman OT, Rudorfer MV, Potter WZ (1989): Idazoxan: a selective alpha 2-antagonist and effective sustained antidepressant in two bipolar depressed patients [letter]. Arch Gen Psychiatry 46:958-959

Page ME, Detke MJ, Dalvi A, Kirby LG, Lucki I (1999): Serotoninergic mediation of the effects of fluoxetine, but not desipramine, in the rat forced swimming test. Psychopharmacology (Berl) 147:162-167

Piercey MF, Smith MW, Lum-Ragan JT (1994): Excitation of noradrenergic cell firing by 5-hydroxytryptamine1A agonists correlates with dopamine antagonist properties. J Pharmacol Exp Ther 268:1297-1303

Pinder RM, Sitsen JM (1987): Alpha 2-adrenoceptor antagonists as antidepressants: the search for selectivity. Psychopharmacol (Berl) 3:107-112

Poirier MF, Boyer P (1999): Venlafaxine and paroxetine in treatment-resistant depression. Double- blind, randomised comparison. Br J Psychiatry 175:12-16

Porsolt RD, Anton G, Blavet N, Jalfre M (1978): Behavioural despair in rats: a new model sensitive to antidepressant treatments. Eur J Pharmacol 47:379-391

Porsolt RD, Bertin A, Blavet N, Deniel M, Jalfre M (1979): Immobility induced by forced swimming in rats: effects of agents which modify central catecholamine and serotonin activity. Eur J Pharmacol 57:201-210

Porsolt RD, Le Pichon M, Jalfre M (1977): Depression: a new animal model sensitive to antidepressant treatments. Nature 266:730-732

Preziosi P, Martire M, Navarra P, Pistritto G, Vacca M (1989): Prolactin-lowering ability of $(+/-)$-idazoxan may be linked to a central noradrenergic-serotonergic interplay. J Pharmacol Exp Ther 249:256-263
Redrobe JP, Bourin M (1998): Dose-dependent influence of buspirone on the activities of selective serotonin reuptake inhibitors in the mouse forced swimming test. Psychopharmacology (Berl) 138:198-206

Redrobe JP, Bourin M (1999): Augmentation of antidepressant pharmacotherapy: a preclinical approach using the mouse forced swimming test. CNS Spectrums 4:73-81

Rénéric JP, Lucki I (1998): Antidepressant behavioral effects by dual inhibition of monoamine reuptake in the rat forced swimming test. Psychopharmacology (Berl) 136:190-197

Routledge C, Marsden CA (1987): Comparison of the effects of selected drugs on the release of hypothalamic adrenaline and noradrenaline measured in vivo. Brain Res 426:103-111

Seth R, Jennings AL, Bindman J, Phillips J, Bergmann K (1992): Combination treatment with noradrenalin and serotonin reuptake inhibitors in resistant depression [see comments]. Br J Psychiatry 161:562-565

Tao R, Hjorth S (1992): Alpha 2-adrenoceptor modulation of rat ventral hippocampal 5-hydroxytryptamine release in vivo. Naunyn Schmiedebergs Arch Pharmacol 345:137-143

Tanda G, Carboni E, Frau R, Di Chiara G (1994): Increase of extracellular dopamine in the prefrontal cortex: a trait of drugs with antidepressant potential? Psychopharmacology (Berl) 115:285-288

Thomas DN, Holman RB (1991): A microdialysis study of the regulation of endogenous noradrenaline release in the rat hippocampus. J Neurochem 56:1741-1746

Tome MB, Isaac MT, Harte R, Holland C (1997): Paroxetine and pindolol: a randomized trial of serotonergic autoreceptor blockade in the reduction of antidepressant latency. Int Clin Psychopharmacol 12:81-89

Weilburg JB, Rosenbaum JF, Biederman J, Sachs GS, Pollack MH, Kelly K (1989): Fluoxetine added to non-MAOI antidepressants converts nonresponders to responders: a preliminary report [see comments]. J Clin Psychiatry 50:447-449

Wieland S, Lucki I (1990): Antidepressant-like activity of 5-HT1A agonists measured with the forced swim test. Psychopharmacology (Berl) 101:497-504

Zanardi R, Franchini L, Gasperini M, Lucca A, Smeraldi E, Perez J (1998): Faster onset of action of fluvoxamine in combination with pindolol in the treatment of delusional depression: a controlled study. J Clin Psychopharmacol 18:441-446 